\title{
ARTICLE OPEN \\ Surface degradation mechanisms in a eutectic high entropy alloy at microstructural length-scales and correlation with phase-specific work function
}

\author{
Vahid Hasannaeimi ${ }^{1}$, Aditya V. Ayyagari ${ }^{1,2}$, Saideep Muskeri ${ }^{1}$, Riyadh Salloom ${ }^{1}$ and Sundeep Mukherjee ${ }^{1}$
}

High entropy alloys represent a new paradigm of structural alloy design consisting of (near) equal proportions of constituent elements resulting in a number of attractive properties. In particular, eutectic high entropy alloys offer a remarkable combination of high strength and good ductility from the synergistic contribution of each phase in the eutectic, thereby circumventing the strength-ductility trade-off in conventional structural materials. In the present study, wear and corrosion behavior were evaluated for the $\mathrm{AlCoCrFeNi} i_{2.1}$ eutectic high entropy alloy consisting of BCC (B2), and FCC ( $\mathrm{L}_{2}$ ) lamellae. A transition from adhesive to oxidative wear was observed in reciprocating wear analysis. The $L 1_{2}$ phase with lower hardness preferentially deformed during the wear test. The ratio of hardness to modulus was almost two times higher for the B2 phase as compared to $\mathrm{L}_{2}$. The overall corrosion resistance of the eutectic high entropy alloy was comparable to 304 stainless steel in $3.5 \mathrm{wt} \% \mathrm{NaCl}$ solution. However, detailed microscopy revealed preferential dissolution of the B2 phase. Phase-specific scanning kelvin probe analysis showed relatively higher electropositivity for the B2 phase as compared with $L 1_{2}$, supporting the selective corrosion and higher coefficient of friction of B2.

npj Materials Degradation (2019)3:16; https://doi.org/10.1038/s41529-019-0079-0

\section{INTRODUCTION}

Multi-principal element alloys represent a new paradigm in the design of advanced materials consisting of (near) equal proportions of constituent elements. These are often termed as high entropy alloys (HEAs) because high configurational entropy suppresses the formation of intermetallic compounds and leads to simple microstructures and attractive engineering properties. In particular, complex-phase HEAs are finding increasing research interest as they bring together the superior properties of singlephase HEAs and precipitation strengthening effects of superalloys. In some of these alloys, the secondary phase is in the form of uniform dispersoids in a single-phase matrix, ${ }^{1,2}$ while for others it is in the form of lamellae as in the case of eutectic HEAs (E-HEAs) such as $\mathrm{AlCoCrFeNi}{ }_{2.1},{ }^{3} \mathrm{Nb}_{25} \mathrm{Sc}_{25} \mathrm{Ti}_{25} \mathrm{Zr}_{25},{ }^{4}$ and $\mathrm{CoCrFeNiNb}{ }_{\mathrm{x}}{ }^{5}$ These alloys demonstrate a unique combination of excellent tensile/compressive strength, good ductility, high hardness, and good oxidation resistance. Slight changes in elemental constituents or thermal processing results in significant enhancement of mechanical properties in eutectic HEAs including tensile and compressive strength as well as elongation. Due to the synergistic contribution of the constituent phases, these alloys are promising in terms of circumventing the strength-ductility trade-off seen in conventional structural materials. Among the reported eutectic HEAs, AlCoCrFeNi ${ }_{2.1}$ E-HEA in particular has been found to be highly tunable, where a wide range of microstructures and excellent mechanical properties have been obtained by thermomechanical processing (such as severe cold rolling ${ }^{6}$ or friction stir processing $\left.{ }^{7}\right)$. Synergistic contribution from ductile face centered cubic $\left(\mathrm{L1}_{2}\right)$ and ordered body centered cubic (B2) phases in this alloy results in a combination of high strength and excellent ductility during tensile deformation. However, there is very limited understanding of the surface degradation behavior for E-HEAs. Use of these alloys as structural engineering materials requires good understanding of their surface degradation mechanisms including corrosion, erosion, and wear behavior. ${ }^{8}$

High wear resistance of single-phase HEAs has been attributed to their relatively higher hardness from solid solution strengthening. ${ }^{9,10}$ In addition, high corrosion resistance of single-phase HEAs stems from the high degree of microstructural homogeneity devoid of local corrosion initiators such as galvanic sites, intermetallic compounds, grain boundary precipitates, and sensitization elements. ${ }^{11-13}$ However, there are limited reports and very little understanding of surface degradation mechanisms in complex-phase and eutectic HEAs. This is not only important from the point of view of fundamental scientific understanding but also in determining the application worthiness of these alloys. Surface degradation studies of complex HEAs reveal unique microstructural dependence in terms of nano-galvanic coupling, ${ }^{14}$ anodic pit initiation, ${ }^{15}$ and grain boundary corrosion ${ }^{16}$ to name a few.

Here, we report on the surface degradation behavior and mechanisms in $\mathrm{AlCoCrFeNi}{ }_{2.1}$ E-HEA. The wear behavior and mechanisms were studied by bulk sliding reciprocating tests while corrosion resistance was evaluated by cyclic polarization and electrochemical impedance spectroscopy (EIS). Phase-specific response in the eutectic was quantified using SKP microscopy to

${ }^{1}$ Department of Materials Science and Engineering, University of North Texas, Denton, TX 76203, USA and ${ }^{2}$ Center for Nanoscale Materials, Argonne National Laboratory, Lemont, IL 60439, USA

Correspondence: Sundeep Mukherjee (Sundeep.Mukherjee@unt.edu)

These authors contributed equally: Vahid Hasannaeimi, Aditya V. Ayyagari

Received: 9 January 2019 Accepted: 25 March 2019

Published online: 12 April 2019 

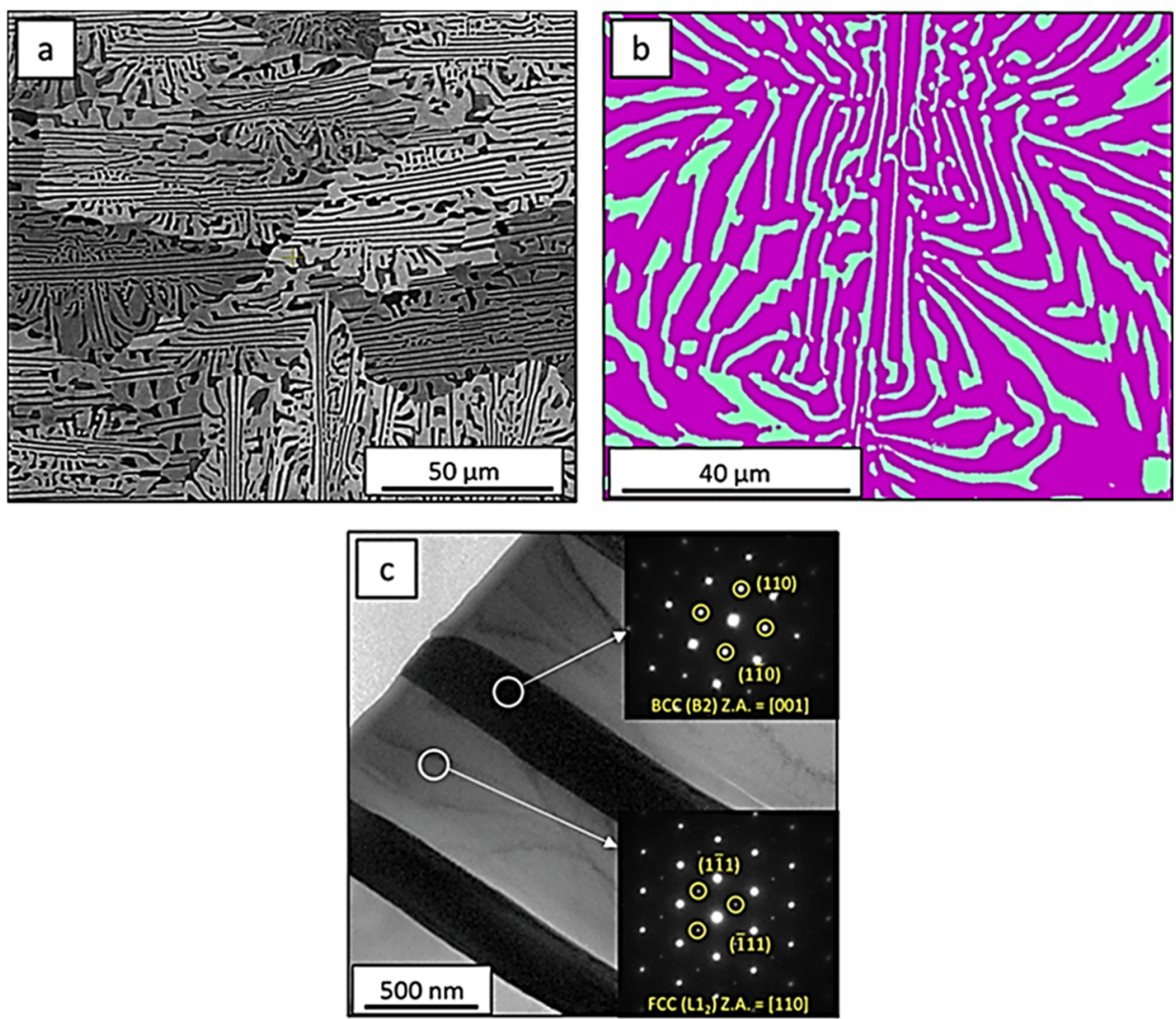

Fig. 1 a Back-scattered electron micrograph of the as-cast AICoCrFeNi ${ }_{2.1}$ alloy and $\mathbf{b}$ EBSD phase map showing the lamellar structure with green and violet colors for $\mathrm{B} 2$ and $\mathrm{L} 1_{2}$ phases, respectively; c TEM bright field image showing the phase contrast for the lamellar structure, the insets show the SADPs obtained using the regions marked with white circles. The zone axis (Z.A.) for B2 and L1 2 phases are [001] and [011], respectively

relate the electronegativity to the electrochemical and friction behavior at the microstructural length-scales. Nano-indentation was used to explain the hardness contribution from each phase to material degradation behavior in terms of wear volume loss while small-scale scratch test was utilized to quantify phase-specific friction behavior.

\section{RESULTS AND DISCUSSION}

The microstructure of the as-cast alloy showed typical lamellar morphology as shown in the back-scattered SEM image in Fig. 1a, with an average grain size of $\sim 75 \pm 25 \mu \mathrm{m}$. Figure $1 \mathrm{~b}$ shows the electron backscatter diffraction (EBSD) phase map of the $L 1_{2} / B_{2}$ lamellar structures. Fine parallel B2 lamellae (green color) are seen distributed within the $\mathrm{L1}_{2}$ phase (violet color). The average thickness of $L 1_{2}$ phase was observed to be $\sim 0.6 \mu \mathrm{m}$ while it was $\sim 0.25 \mu \mathrm{m}$ for the B2 phase. The volume fraction of $\mathrm{L}_{2}$ was $\sim 68 \%$ while B2 was $32 \%$. TEM analysis was performed to confirm the presence of ordered $\mathrm{L} 1_{2} / \mathrm{B} 2$ phases as shown in Fig. 1c. Distinct contrast can be seen in the lamellae regions, bright and dark for $\mathrm{L}_{1}$ and $\mathrm{B} 2$, respectively. The inset in Fig. 1c shows the selected area diffraction patterns (SAEDs) obtained from the two phases. The presence of super-lattice spots in both SAEDs confirms the $\mathrm{L}_{2}$ and B2 ordered structures. Energy dispersive X-ray spectroscopy (EDS) mapping of the alloy showed different compositions for $\mathrm{L}_{2}$ and B2 as summarized in Table 1.

Wear resistance of the AlCoCrFeNi ${ }_{2.1}$ E-HEA was quantified by sliding reciprocating wear tests. SEM images of wear tracks obtained after 2 min up to $120 \mathrm{~min}$ of sliding duration are shown in Fig. 2 in secondary electron and back-scattered electron modes. The wear track obtained after 2 min sliding predominantly showed patches of

\begin{tabular}{|c|c|c|c|c|c|}
\hline \multirow[t]{2}{*}{ Phase } & \multicolumn{5}{|c|}{ Elements (at. \%) } \\
\hline & Al & Co & $\mathrm{Cr}$ & $\mathrm{Fe}$ & $\mathrm{Ni}$ \\
\hline $\mathrm{L}_{2}$ & $6.4 \pm 0.3$ & $18.4 \pm 0.3$ & $23.1 \pm 0.4$ & $20.5 \pm 0.4$ & $31.6 \pm 0.5$ \\
\hline B2 & $15.7 \pm 0.7$ & $15.1 \pm 0.2$ & $14.0 \pm 0.3$ & $14.9 \pm 0.2$ & $40.3 \pm 0.7$ \\
\hline
\end{tabular}

re-deposited material, an indication of adhesive wear. However, no significant stiction of wear debris or wear particles were observed on the ball. This may be attributed to the continual dislodging of particles from the counterface during sliding-reciprocation action.

The back-scattered electron images in Fig. 2 clearly show increasing darker phase with increasing sliding duration, indicating a gradual transition in wear mechanism. A high magnification image of the wear track after 120 min sliding duration is shown in Fig. 3a while the EDS map of the surface close to the wear track edge (red box in Fig. 3a) is shown in Fig. 3b. The wear track was characterized by high concentration of oxygen (up to 24 at.\%), which indicates oxidation of the surface from temperature rise during sliding. The extent of surface oxidation increased almost linearly with increasing sliding duration as deduced from Fig. 2 and corresponding EDS spectra. To evaluate the nature of the oxide scale on wear track, Raman spectroscopy was done for the sample and wear debris following the test. The Raman spectrum in Fig. $3 c$ shows several overlapping peaks in the $700-1400 \mathrm{~cm}^{-1}$ range. These correspond to complex oxides of transition metals present in the alloy including $\mathrm{Ni}, \mathrm{Cr}$, and $\mathrm{Co}$. The strong peak at 

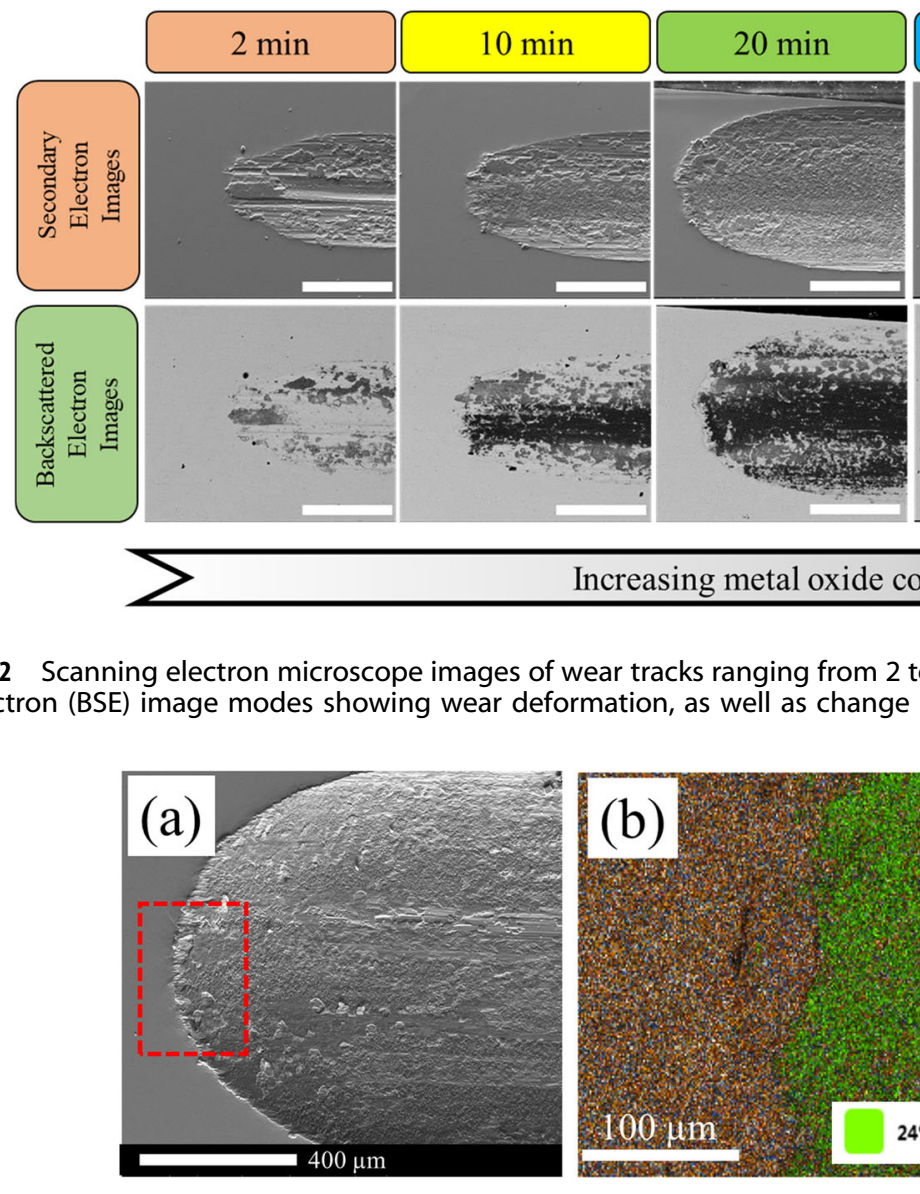
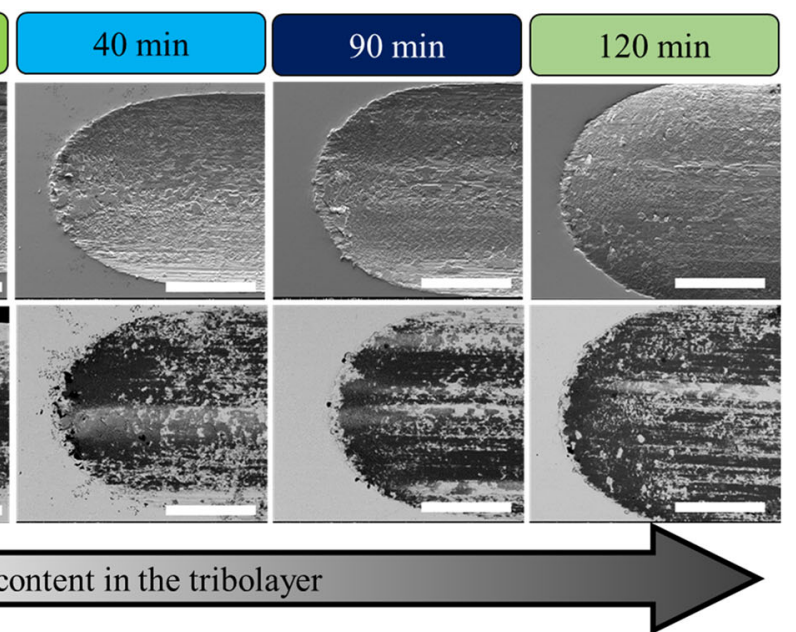

Fig. 2 Scanning electron microscope images of wear tracks ranging from 2 to 120 min duration in secondary electron (SE) and back-scattered electron (BSE) image modes showing wear deformation, as well as change in wear mechanism. The white scale bar corresponds to $400 \mu \mathrm{m}$
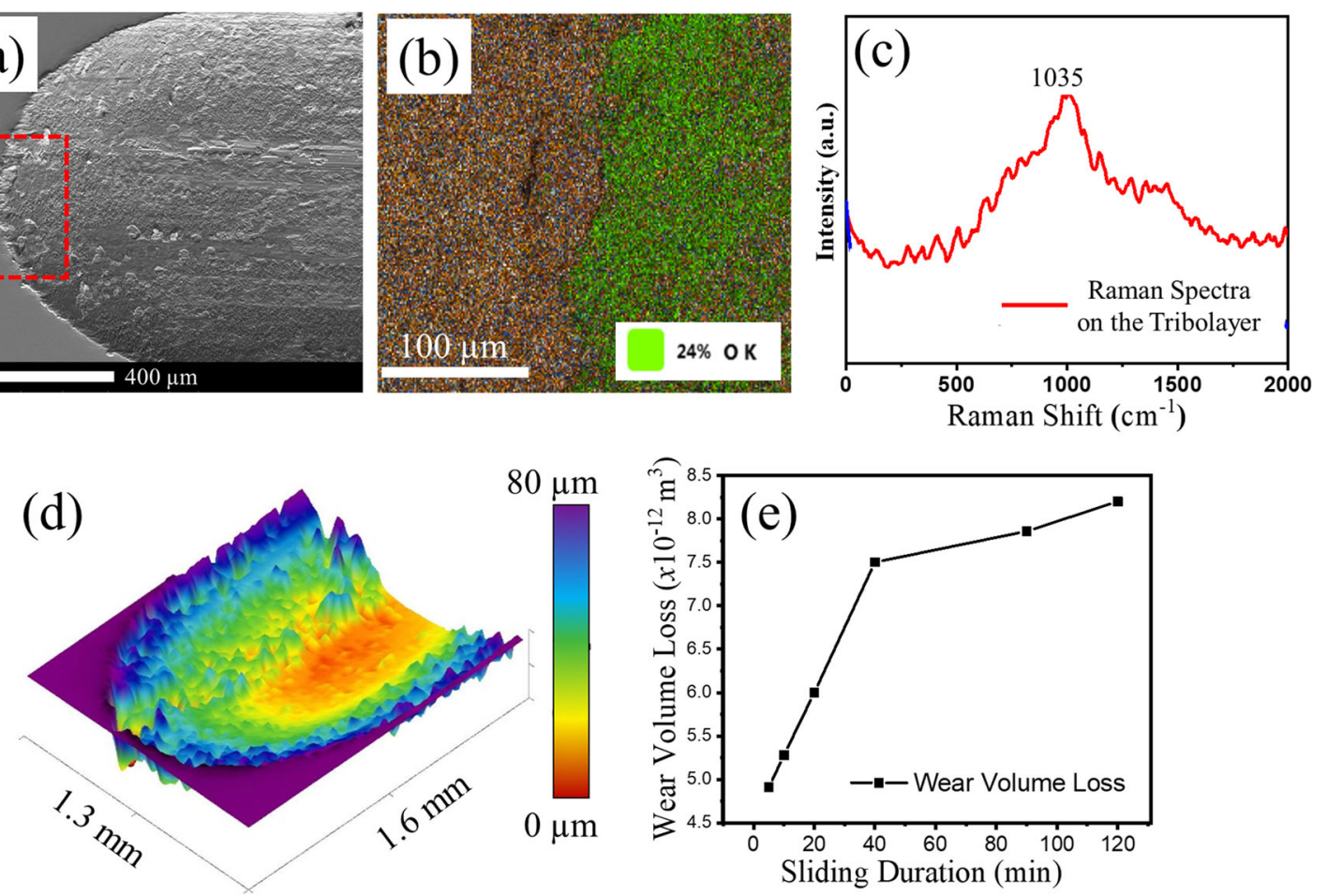

Fig. 3 a Scanning electron microscope image of wear track after 120 min of sliding b EDS map showing oxides formed on the surface c Raman spectrum of the oxide scale showing presence of complex cobalt oxides $\mathbf{d}$ 3D interferometry image showing wear track depth and material loss during sliding; e wear volume loss as function of sliding duration

$1035 \mathrm{~cm}^{-1}$ closely matched with the position for Cobalt oxide, indicating that $\mathrm{CoO}_{x}$ formation was tribologically favorable. ${ }^{17,18}$ Complex Cobalt-Chromium oxides have been reported to be typically present in tribofilms and passivation layers of alloys containing the respective elements providing surface protection from aggressive degradation. ${ }^{19,20}$ A $3 D$ reconstruction of the wear track obtained using white light interferometry is shown in Fig. $3 \mathrm{~d}$.

The wear track depth was $\sim 80 \mu \mathrm{m}$, indicating relatively higher wear volume loss compared to other recently studied complex HEAs. ${ }^{21}$ The wear volume loss quantified using Gwyddion software is shown in Fig. 3e as a function of sliding duration. There was a clear change in slope of wear volume after about $40 \mathrm{~min}$ from $2.05 \times 10^{-12} \mathrm{~m}^{3}$ per minute of material loss to lower rate of $0.25 \times$ $10^{-12} \mathrm{~m}^{3}$ per minute. This may be an indicator of two distinct mechanisms. The steep initial wear rate may be due to the dominant adhesive wear with aggravated material loss due to the absence of protective tribolayers. Subsequently, the wear volume loss continued to increase but the rate of material loss was an order of magnitude lower from the formation of protective oxide tribolayer (oxidative mechanism). The magnitude of friction coefficient during the initial wear regime was higher at $0.65-0.70$ and gradually lowered to $0.45-0.50$ with progressive sliding. The initial higher friction coefficient may be attributed to the high metal-metal contact and inherently electropositive nature of the constituent elements that promotes strong adhesion. $^{22}$ However, the subsequently formed oxide and tribolayer may have effectively lowered the friction values after longer sliding distance. Besides wear track and macroscopic oxide 
formation, the material was observed to undergo complex microscopic deformation as observed from the post-test microstructures.

The surface deformation mechanisms during wear were studied to gain fundamental understanding of the tribological system and material response to fatigue type loading, given the nature of repetitive sliding under a heavy normal load. Figure 4 a shows surface deformation adjacent to the wear track after $120 \mathrm{~min}$ sliding. Extensive slip deformation was seen for the bright $\mathrm{L1}_{2}$ phase while no significant deformation was seen in case of the darker B2 phase. A high magnification image of the inset area (Fig. 4b) shows extensive slip lines in the $\mathrm{L1}_{2}$ phase discontinued at the $\mathrm{L}_{2}-\mathrm{B} 2$ interface. The image also shows material dislodged from the counterface and deposited on to the edge of the wear track during sliding. Both phases deformed uniformly inside the wear track, and no inter-phase debonding or void formation is observed in Fig. 4c. It was recently reported that $L 1_{2}$ phase can accommodate several arrays of parallel mobile dislocations and deform by planar slip. ${ }^{23}$ This is due to the splitting of $\frac{1}{2}\langle 111\rangle$ dislocation into $\frac{1}{6}\langle 112\rangle$ Shockley partials and the formation of stacking faults between them. This restricts the slip to the $\{111\}$ plane and effectively minimizes cross-slip. This is a characteristic feature of slip occurring in low stacking fault energy materials. B2 phase in the eutectic has been shown to fail in a brittle manner while $\mathrm{L}_{2}$ phase shows ductility and necking, leading to dualmode fracture in this alloy. ${ }^{23}$ Our wear tests indicate that $\mathrm{L}_{2}$ and B2 phases may deform simultaneously, while B2 phase can accommodate medium density of dislocations. This was attributed to the $3 \mathrm{D}$ back-stress acting on $\mathrm{L}_{2}$ phase which can maintain synchronous deformation in heterogeneous systems. This back stress is further enhanced by semi-coherent boundaries between $B 2$ and $L_{1}$ phases, and the lower fraction of $B 2$ lamellae. The accumulative effect of these conditions resulted in the activation of dislocation in the brittle B2 phase facilitated by high density of dislocation pile-up at the phase boundaries, and this modified the brittle behavior of B2 phase to accommodate deformation.

To understand the wear mechanism at microstructural lengthscale, phase-specific scratch behavior was evaluated with in situ observation of material removal mechanism. The variation in coefficient of friction (COF) across the scratch line is shown in Fig. 5a. The average COF for $\mathrm{L}_{2}$ was found to be $\sim 0.82$, while it was $\sim 0.87$ for the B2 phase. This is consistent with the bulk wear results which showed greater extent of deformation for $L 1_{2}$ due to activation of multiple slip systems. As seen in the inset of Fig. 5a, almost no material was observed adhering to the cube-corner indenter. Furthermore, the material pile-up was different along the scratch line, as shown in Fig. 5b, with much larger amount of pileup for $\mathrm{L} 1_{2}$ compared to $\mathrm{B} 2$.

Phase-specific hardness and modulus measurements by nanoindentation are summarized in Table 2, with the loaddisplacement curves shown in Fig. 6a. The B2 phase showed lower maximum displacement $(\sim 225 \mathrm{~nm})$ as compared to $\mathrm{L}_{2}$ phase that had a peak displacement of $275 \mathrm{~nm}$ at $10 \mathrm{mN}$ load. The location of the indent on the $B 2$ and $L 1_{2}$ phases are shown in Fig. $6 \mathrm{~b}, \mathrm{c}$, respectively. At least ten indentations were performed on each phase. The B2 phase showed a hardness of $4.9 \pm 0.71 \mathrm{GPa}$,
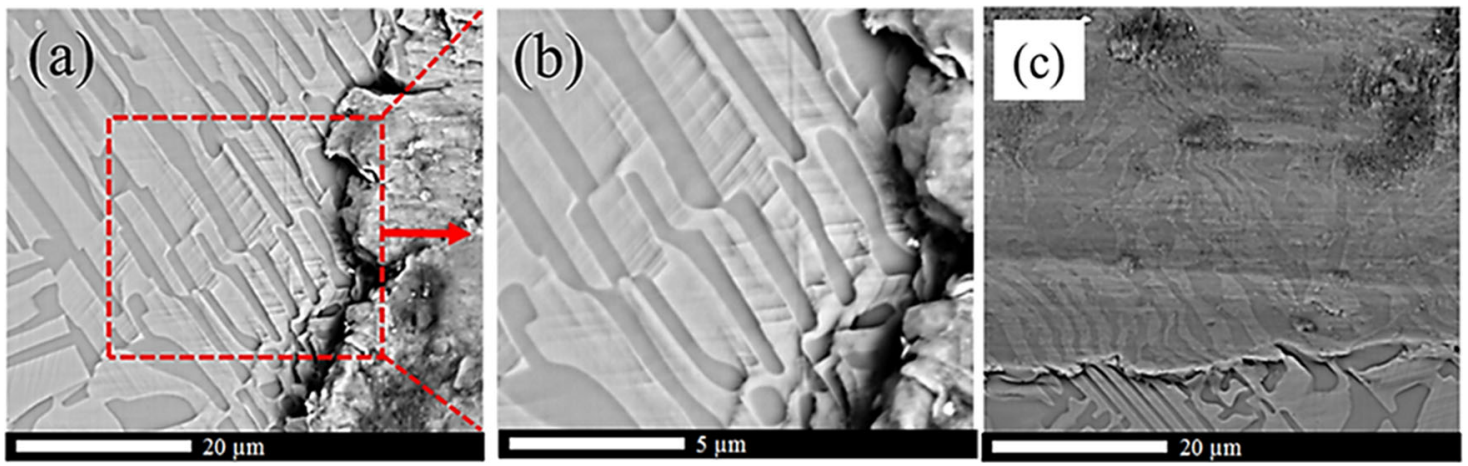

Fig. 4 a Low magnification SEM image showing deformation at the edge of the wear track $\mathbf{b}$ zoomed-in view corresponding to the square box showing extensive slip deformation for the bright L12 phase while no significant deformation was seen for the dark B2 phase $\mathbf{c}$ wear surface inside the track showing no preferred deformation of either of the two phases
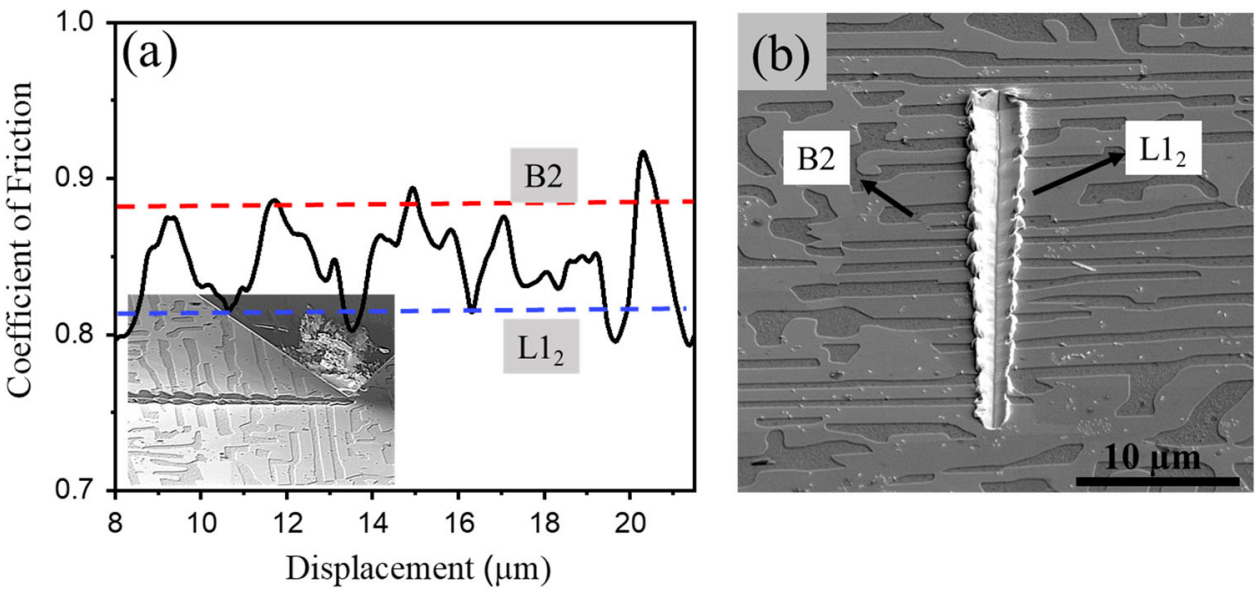

Fig. 5 a Coefficient of friction variation as a function of displacement measured using pico-indentation on the E-HEA; the inset shows SEM image of the cube-corner indenter during the in situ experiment; $\mathbf{b}$ SEM image of the scratch line showing different amounts of material pileup 
while the $\mathrm{L}_{1}$ phase showed a hardness of $4.03 \pm 0.39 \mathrm{GPa}$. The ratio of hardness to modulus was significantly higher for the B2 phase as compared to the $\mathrm{L1}_{2}$ phase.

Although hardness is the dominant parameter which affects friction and wear behavior according to Archard's relation, ${ }^{24}$ recent studies have shown that modulus also significantly affects wear resistance. ${ }^{24}$ The ratio of hardness to modulus represents deformation relative to yielding. ${ }^{25,26}$ The ratio of $\mathrm{H} / \mathrm{E}^{*}$ calculated from nano-indentation are shown in Table 2. The B2 phase showed a higher ratio $(\sim 0.027)$ compared to $L 1_{2}$ phase $(\sim 0.018)$. A high $\mathrm{H} / \mathrm{E}^{*}$ ratio material shows greater elastic strain prior to plastic deformation compared to a lower $\mathrm{H} / \mathrm{E}^{*}$ material. ${ }^{27}$ Thus, high $\mathrm{H} / \mathrm{E}^{*}$ ratio materials are expected to exhibit better wear resistance. As shown in Fig. $4 \mathrm{~b}$, the darker $\mathrm{B} 2$ phase with higher $\mathrm{H} / \mathrm{E}^{*}$ value was almost un-deformed during reciprocating wear test while the brighter $\mathrm{L} 1_{2}$ phase with lower $\mathrm{H} / \mathrm{E}^{*}$ value was plastically deformed showing extensive slip lines. A larger plastic strain was induced within the region with smaller $\mathrm{H} / \mathrm{E}^{*}$ ratio which led to higher contact area during wear and more material loss.

The corrosion resistance of the alloys was evaluated using accelerated electrochemical tests. The variation of open circuit potential (OCP) with immersion time in $0.6 \mathrm{M}$ (3.5 wt.\%) $\mathrm{NaCl}$ is

\begin{tabular}{|llll|}
\hline Table. 2. & Hardness and modulus values from nano-indentation \\
\hline Phase & $\begin{array}{l}\text { Avg. hardness } \mathrm{H} \\
(\mathrm{GPa})\end{array}$ & $\begin{array}{l}\text { Avg. modulus } \mathrm{E}^{*} \\
(\mathrm{GPa})\end{array}$ & $\begin{array}{l}\text { Hardness to } \\
\text { modulus ratio }\left(\mathrm{H} / \mathrm{E}^{*}\right)\end{array}$ \\
\hline $\mathrm{L} 1_{2}$ & $4.03 \pm 0.39$ & $216.05 \pm 23.89$ & 0.0186 \\
$\mathrm{~B} 2$ & $4.9 \pm 0.71$ & $180.07 \pm 10.34$ & 0.0270 \\
\hline
\end{tabular}

shown in Fig. 7a. The alloy surface gradually developed a protective passive layer as evidenced by the continuous increase in voltage towards nobler potentials. The OCP stabilized after $\sim 6 \mathrm{ks}$. Following steady-state condition, the sample was perturbed with a small $A C$ voltage $(5 \mathrm{mV})$ and electrochemical impedance spectrum (EIS) was recorded. The EIS data are represented in the form of a Nyquist plot as shown in Fig. 7b. The shape of the Nyquist plot is an incomplete arc, the radius of which is directly proportional to the surface polarization resistance of the alloy. The curve was best-fitted with a modified Randles circuit to quantify the electrochemical parameters, namely charge transfer resistance $\left(R_{\mathrm{ct}}\right)$, solution resistance $\left(R_{\mathrm{s}}\right)$ and a constant phase element (CPE) to account for the heterogeneities of the surface. ${ }^{28}$ The impedance of a CPE is defined as follows:

$Z_{\mathrm{CPE}}=\left[Q(j \omega)^{n}\right]^{-1}$

where $j^{2}=-1, \omega$ is the angular frequency, $Q$ is the magnitude of the CPE, and $n$ is the exponent of the CPE related to the roughness of the surface. ${ }^{29}$ The value of $n$ is a measure of the deviation from pure capacitive behavior $(n=1)$. The values of the electrochemical parameters associated with the corrosion behavior of E-HEA and 304 stainless steel in $3.5 \mathrm{wt} . \% \mathrm{NaCl}$ and the simulated values for the equivalent circuit elements are summarized in Table 3 . Due to the high resistance of the surface charge transfer, only a portion of capacitive loop was formed in the range of frequency in Nyquist plot. There is no indication of a second loop from adsorptive film on the specimen surface. ${ }^{30}$ Although the E-HEA showed less noble behavior during potential-time experiment, it exhibited a higher charge transfer resistance than 304 stainless steel. Cyclic polarization tests were carried out after the EIS test (Fig. 7c), in which a corrosion current density $\left(\mathrm{i}_{\text {corr }}\right)$ of $60 \mathrm{nA} / \mathrm{cm}^{2}$ was achieved in $\mathrm{NaCl}$, similar to values typically seen for austenitic stainless steel (types 304 and $316 \mathrm{~L}){ }^{16,31}$ The eutectic HEA showed a passivation range
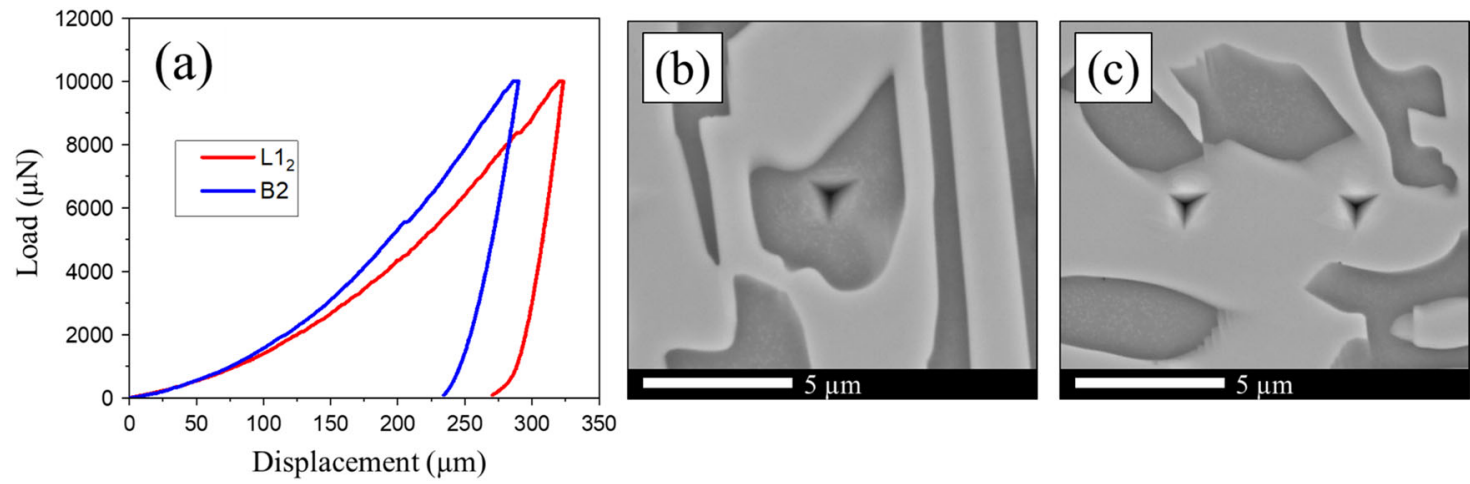

Fig. 6 a Load-displacement curves obtained from nano-indentation; SEM image of an indent: $\mathbf{b}$ on the B2 phase and $\mathbf{c}$ on the L12 phase
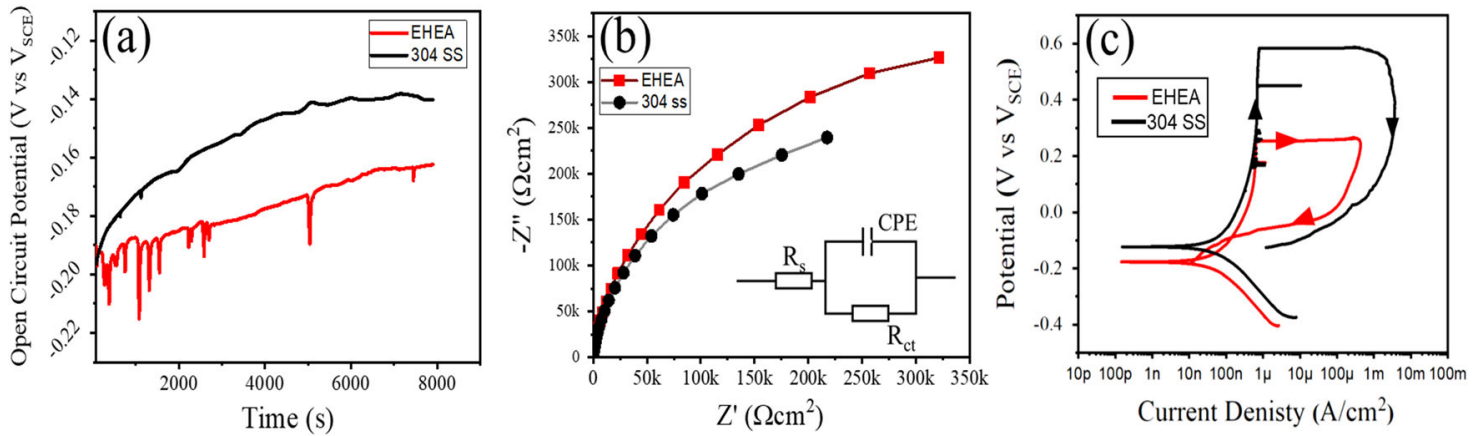

Fig. 7 a Open circuit potential obtained by holding the sample in $3.5 \mathrm{wt} . \% \mathrm{NaCl}$ solution, the potential stabilized after $6 \mathrm{ks}$; $\mathbf{b}$ EIS test showing Nyquist plot with Randles circuit fit; c cyclic polarization plot obtained at a scan rate of $0.25 \mathrm{mV} / \mathrm{s}$ 
Table 3. Electrochemical parameters and equivalent circuit element values for ElS data for AlCoCrFeNi ${ }_{2.1}$ alloy in $3.5 \mathrm{wt} . \% \mathrm{NaCl}$ solution

\begin{tabular}{|c|c|c|c|c|c|c|c|}
\hline & $E_{\text {corr }}(\mathrm{mV}$ vs. SCE) & Passivation range, $(\mathrm{mV})$ & $i_{\text {corr }}(\mathrm{nA} / \mathrm{cm} 2)$ & $\mathrm{R}_{\mathrm{s}}\left(\Omega . \mathrm{cm}^{2}\right)$ & $\begin{array}{l}\mathrm{CPE} \\
\left(\mathrm{S} \mathrm{s}^{n} \mathrm{~cm}^{-2}\right)\end{array}$ & $\mathrm{R}_{\mathrm{ct}}\left(\Omega \cdot \mathrm{cm}^{2}\right)$ & $\mathrm{n}$ \\
\hline E-HEA & -177 & 388 & 60 & 5.98 & $1.71 \times 10^{-5}$ & $5.23 \times 10^{5}$ & 0.93 \\
\hline
\end{tabular}
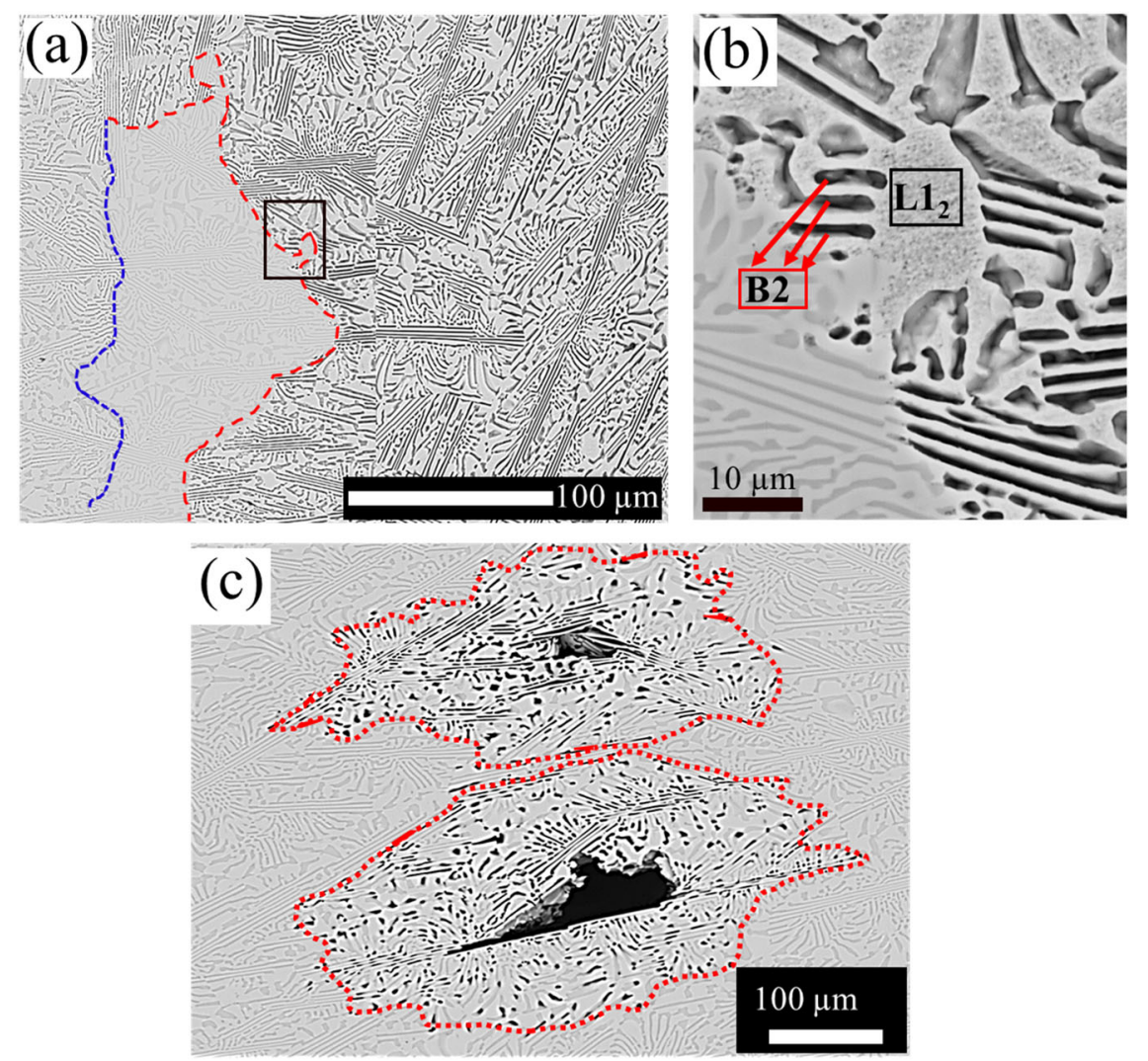

Fig. 8 a Low magnification SEM image of E-HEA after polarization test in $3.5 \mathrm{wt} \% \mathrm{NaCl}$ solution; b high magnification SEM image corresponding to the black box in the previous image showing preferential dissolution of B2 phase; c pitting in the corroded sample with pit initiation in the region with high B2 phase fraction

$\left(E_{\text {pit }}-E_{\text {corr }}\right)$ of $\sim 400 \mathrm{mV}$, which is lower than the range for 304 stainless steel $(\sim 700 \mathrm{mV})$. However, the area under the positive hysteresis loop in cyclic polarization plot was lower for EHEA as compared with stainless steel, which could be an indication of less pitting susceptibility of E-HEA. The repassivation of the E-HEA during the potential reverse cycle occurred at $-100 \mathrm{mV}$ vs. SCE.

SEM images of the corroded surfaces are shown in Fig. 8. Initial material removal comprised of uniform dissolution of B2 phase relative to $L 1_{2}$ phase. This may be due to lower concentration of corrosion resistant elements such as $\mathrm{Cr}$ and $\mathrm{Co}$ in $\mathrm{B} 2$ phase relative to $L 1_{2}$ phase. Figure 8 a reveals that corrosion propagation was selective to grain orientation. Three regions are delineated with dotted lines along the grain boundaries. In Fig. 8a, the area delineated with blue line was observed to undergo mild corrosion whereas patches similar to the ones sandwiched between blue and red regions did not undergo any corrosion and remained intact. The separation between the corroded and pristine regions was along the grain boundaries. The region beyond the red boundary showed preferential corrosion of the B2 phase. The preferential dissolution of $B 2$ relative to $\mathrm{L}_{2}$ was observed at higher magnifications (Fig. 8b). However, the unaffected grains did not show any signature of selective dissolution of B2. The second mechanism observed in samples that were subjected to higher anodic currents was pitting, which was always preceded by localized corrosion of a grain wherein B2 phase was rapidly depleted. The extent of corrosion on the susceptible grains was again clearly defined by the grain boundaries, indicating that certain orientations were more prone to corrosion in the matrix. Confluence of material depleted triple junctions of B2 phase developed into a pit as seen in Fig. 8c.

For further understanding of localized electrochemical activity of the eutectic microstructure, SKP analysis was done to determine the relative work-function map. As shown in Fig. 9, the relative work function varied over the surface, when the probe scanned the surface at a constant distance of $50 \mu \mathrm{m}$. The regions with higher work function corresponded to $\mathrm{L}_{2}$ while the $\mathrm{B} 2$ phase showed lower work function (Fig. 9a). The parallel arrangement of the B2 lamellae within $L_{1}$ phase is better observed in 2D SKP potential map (Fig. 9b). The correlation between corrosion potential and work function investigated for crystalline ${ }^{32}$ and amorphous $^{33}$ materials show that metallic alloys with higher work function typically show better corrosion resistance due to lower electropositivity. ${ }^{34}$ In other words, corrosion is affected by the 
(a)

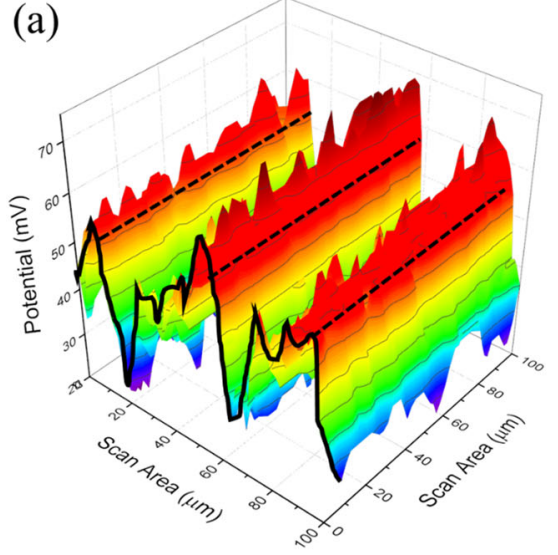

(b)

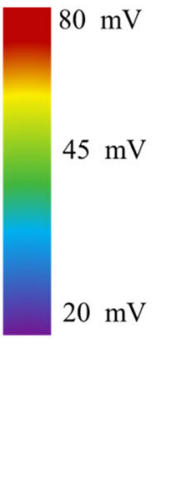

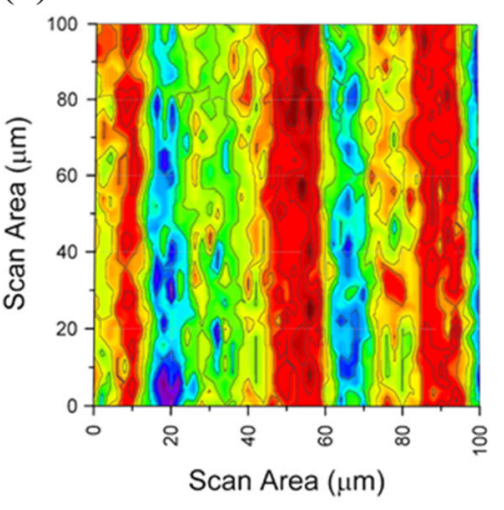

Fig. 9 Relative work-function topography obtained from scanning kelvin probe microscope of the phases shown in a Isometric view to delineate the potential changes and $\mathbf{b}$ top view to delineate the width of the bands corresponding to phases. The high work-function regions correspond to L12 whereas lower work-function regions are related to B2 lamellae

\begin{tabular}{|lllllr|}
\hline Table 4. & A comparison of wear and corrosion properties of $\mathrm{B} 2$ and $\mathrm{L} 1_{2}$ \\
\hline & Phase & $\begin{array}{l}\text { Crystal } \\
\text { structure }\end{array}$ & SKP signature & $\begin{array}{l}\text { Corrosion } \\
\text { affinity }\end{array}$ & COF \\
\hline B2 & Darker & Ordered-bcc & Electropositive & More active & 0.87 \\
$\mathrm{L1}_{2}$ & Brighter & Ordered-fcc & Electronegative & More noble & 0.81 \\
\hline
\end{tabular}

surface electron behavior or electron activity, which may be characterized by work function..$^{35}$ Hence, the corrosion potential is affected by the local work function. ${ }^{36}$ In case of eutectic HEA, L1 $1_{2}$ phase was found to be more resistant to corrosion due to its higher work function, indicating that electron release may be more difficult for $\mathrm{L1}_{2}$. The difference in work function of the present phases facilitates galvanic corrosion in addition to grainorientation dependent uniform corrosion. As shown in Fig. 8b, B2 phase got selectively removed due to its lower corrosion resistance, while $\mathrm{L}_{2}$ phase was slightly corroded. Hence, in addition to the difference in chemistry of the two phases in the eutectic, the formation of galvanic coupling may be explained from the work-function variations over the surface.

The difference in work function and electropositivtiy of $\mathrm{B} 2 / \mathrm{L}_{2}$ supports the scratch behavior of the alloy as well. Higher adhesion for metal-on-metal wear has been reported for more electropositive alloys. ${ }^{34}$ Buckley's hypothesis ${ }^{37}$ suggests that chemically active metals (i.e., electron donors) are prone to strong adhesion as opposed to inert metals. ${ }^{38}$ Therefore, it can be concluded that the more electropositive nature of B2 phase might have resulted in a stronger adhesion to the cube-corner indenter and resulted in higher localized stresses (Fig. 5a).

Surface degradation behavior of a two-phase E-HEA, AlCoCr$\mathrm{FeNi}_{2.1}$, was investigated. The wear behavior was observed to linearly increase with increasing sliding duration (Fig. 3). The mechanism of wear was initially abrasive wear that gradually transitioned into oxidation wear with prolonged sliding. Corrosion current density was comparable to 304 stainless steel (Fig. 7). Corrosion was predominantly galvanic, with the $\mathrm{B} 2$ having more anodic character than the $\mathrm{L}_{2}$ phase. The corrosion behavior of the alloys was observed to have a close correlation with the relative work-function values of the two phases: $\mathrm{LI}_{2}$ phase with higher work function showed higher corrosion resistance, while B2 phase with relatively lower work function was more susceptible to dissolution (Fig. 9). The difference in electronegativity from variation in work function explained the phase-specific friction and scratch behavior, as well. For overall comparison, the properties of each phase are summarized in Table 4.

\section{METHODS}

The AlCoCrFeNi ${ }_{2.1}$ E-HEA was cast by melting weighted proportions of pure elements in a vacuum arc-melter. The alloy was homogenized by melting at least five times followed by removal of surface defects and imperfections. The alloy was cut, mounted, and polished to a mirror finish for microscopy and nano-indentation studies. The density of the alloy was calculated by determining volume using AccuPyc gas pycnometer and mass using Sartorius sensitive balance. FEI Quanta scanning electron microscope (SEM) with built-in EDS was used for microstructure evaluation. At least five area scans were performed at different regions to determine the composition of each phase. EBSD analysis was conducted using $\mathrm{FEI}$ Nova Nano SEM230. Transmission electron microscopy (TEM) imaging was performed using Philips EM-420 operating at $120 \mathrm{kV}$. TEM foil was prepared by FEI Nova NanoLab 200 focused ion beam (FIB) system. The average grain size was calculated using a linear mean intercept method from the SEM images of several grains using ImageJ digital micrograph analysis software.

The wear and friction response of the alloy was evaluated using RTEC Universal Tribometer with a sliding reciprocating stage. Wear tests were carried out at a load of $10 \mathrm{~N}$, stroke length of $1 \mathrm{~mm}$, and reciprocating frequency of $5 \mathrm{~Hz}$. Sliding duration was progressively increased from 2 to $120 \mathrm{~min}$. Wear volume loss was quantified using white light interferometry. Nano-indentation was done using TI-Premier Triboindenter (Bruker) using a diamond Berkovich tip at room temperature. Maximum load used was $10,000 \mu \mathrm{N}$ with loading time of $2 \mathrm{~s}$, holding time of $5 \mathrm{~s}$, and unloading time of $2 \mathrm{~s}$. Raman spectroscopy (Nicolet Almega XR) with a near infrared laser (NIR, $\lambda=780 \mathrm{~nm}$ ) was performed over the wear tracks to evaluate the nature of wear debris. To evaluate the phase-specific friction, a Picoindenter (PI 88 Hysitron Inc.) was used inside a FEI Nova NanoLab 200 FIB microscope. A diamond cube-corner tip was used to perform the scratch across the two phases with a load of $3000 \mu \mathrm{N}$. At least five tests were performed in various regions to determine the repeatability for the COF.

Corrosion resistance was evaluated using Gamry Ref3000 potentiostat. A three electrode system was used with saturated calomel electrode (SCE) as reference, Pt wire as counter, and the sample as working electrode. Corrosion behavior was evaluated in $3.5 \mathrm{wt} . \%(0.6 \mathrm{M}) \mathrm{NaCl}$ solution. OCP was determined by immersing the sample into solution with no external bias. Following a stable OCP, EIS was carried out from $10^{-2}$ to $10^{6} \mathrm{~Hz}$ at a rate of 10 points per decade. The EIS measurements were carried out at $5 \mathrm{mV}$ rms bias for external perturbation. Following EIS measurement, cyclic polarization test was carried out by scanning the sample at a rate of $0.25 \mathrm{mV} / \mathrm{s}$ from $-200 \mathrm{mV}$ with respect to OCP up to stable pitting, and then the potential sweep direction was reversed. The pitting morphology was evaluated using scanning electron microscopy. Phase-specific electrochemical behavior was evaluated by a Princeton Applied Research SKP to determine the relative work function over an area of $100 \mu \mathrm{m}^{2}$. A tungsten wire was used as a reference probe during SKP measurements. A high resolution topography map of the specimen was recorded to enable the use of constant height mode for SKP analysis. Work function was determined at a working distance of $50 \mu \mathrm{m}$ with lab air (RH 55\%) forming the capacitor between the $\mathrm{W}$ probe and working electrode. 


\section{DATA AVAILABILITY}

All data generated or analysed during this study are included in this published article. Further information is available on request from the authors.

\section{AUTHOR CONTRIBUTIONS}

V.H. performed bulk corrosion experiments, SKP experiments, microscopy of corroded samples, and data analysis; A.V.A. performed accelerated corrosion and bulk wear experiments, microscopy of wear samples, and data analysis; S.Muskeri. conducted nano-indentation and pico-scratch experiments. R.S. cast and processed the materials, performed SEM, TEM characterization; and S.Mukherjee. supervised the work. All the authors discussed and contributed to the writing of the manuscript.

\section{ADDITIONAL INFORMATION}

Competing interests: The authors declare no competing interests.

Publisher's note: Springer Nature remains neutral with regard to jurisdictional claims in published maps and institutional affiliations.

\section{REFERENCES}

1. Ayyagari, A. V., Gwalani, B., Muskeri, S., Mukherjee, S. \& Banerjee, R. Surface degradation mechanisms in precipitation-hardened high-entropy alloys. NPJ Materials Degradation. 2, 1-10 (2018).

2. Wang, R., Zhang, K., Davies, C. \& Wu, X. Evolution of microstructure, mechanical and corrosion properties of AlCoCrFeNi high-entropy alloy prepared by direct laser fabrication. J. Alloys Compd. 694, 971-981 (2017).

3. Lu, Y. et al. A promising new class of high-temperature alloys: eutectic high entropy alloys. Sci. Rep. 4, 1-5 (2014).

4. Rogal, L., Morgiel, J., Świątek, Z. \& Czerwiński, F. Microstructure and mechanical properties of the new $\mathrm{Nb}_{25} \mathrm{Sc}_{25} \mathrm{Ti}_{25} \mathrm{Zr}_{25}$ eutectic high entropy alloy. Mater. Sci. Eng. A 651, 590-597 (2016).

5. He, F. et al. Designing eutectic high entropy alloys of CoCrFeNiNb . J. Alloys Compd. 656, 284-289 (2016).

6. Wani, I. S. et al. Ultrafine-grained AlCoCrFeNi ${ }_{2.1}$ eutectic high-entropy alloy. Mater. Res. Lett. 4, 174-179 (2016).

7. Nene, S. S. et al. Enhanced strength and ductility in a friction stir processing engineered dual phase high entropy alloy. Sci. Rep. 7, 1-7 (2017).

8. Qiu, Y., Thomas, S., Gibson, M. A., Fraser, H. L. \& Birbilis, N. Corrosion of high entropy alloys. NPJ Materials Degradation 1, 1-18 (2017).

9. $\mathrm{Wu}$, J. et al. Adhesive wear behavior of $\mathrm{Al}_{\mathrm{x}} \mathrm{CoCrCuFeNi}$ high-entropy alloys as a function of aluminum content. Wear 261, 513-519 (2006).

10. Tong, $\mathrm{C}$. et al. Mechanical performance of the $\mathrm{Al}_{\mathrm{x}} \mathrm{CoCrCuFeNi}$ high-entropy alloy system with multiprincipal elements. Metall. Mater. Trans. A 36A, 1263-1271 (2005).

11. Chou, Y., Yeh, J. \& Shih, H. The effect of molybdenum on the corrosion behaviour of the high-entropy alloys $\mathrm{Co}_{1.5} \mathrm{CrFeNi}_{1.5} \mathrm{Ti}_{0.5} \mathrm{Mo}_{x}$ in aqueous environments. Corros. Sci. 52, 2571-2581 (2010).

12. Qiu, X., Zhang, Y., He, L. \& Liu, C. Microstructure and corrosion resistance of AlCrFeCuCo high entropy alloy. J Alloys Compounds. 549, 195-199 (2013).

13. Ayyagari, A., Hasannaeimi, V., Grewal, H. S. \& Mukherjee, S. Corrosion, erosion and wear behavior of complex concentrated alloys: a review. Metals 8, 603-643 (2018).

14. Lin, C.-M. et al. Evolution of microstructure, hardness, and corrosion properties of high-entropy $\mathrm{Al}_{0.5} \mathrm{CoCrFeNi}$ alloy. Intermetallics 19, 288-294 (2011).

15. Lee, C., Chang, C., Chen, Y. Y., Yeh, J. W. \& Shih, H. C. Effect of the aluminium content of $\mathrm{Al}_{\mathrm{x}} \mathrm{CrFe}_{1.5} \mathrm{MnNi}_{0.5}$ high-entropy alloys on the corrosion behaviour in aqueous environments. Corros. Sci. 50, 2053-2060 (2008).

16. Hsu, Y.-J., Chiang, W.-C. \& Wu, J.-K. Corrosion behavior of $\mathrm{FeCONiCrCu}_{\mathrm{x}}$ highentropy alloys in $3.5 \%$ sodium chloride solution. Mater. Chem. Phys. 92, 112-117 (2005).

17. Li, L., Kim, D. Y. \& Swain, G. M. Transient formation of chromate in trivalent chromium process (TCP) coatings on AA2024 as probed by Raman spectroscopy. J. Electrochem. Soc. 159, 326-333 (2012).
18. Li, Y. et al. Identification of cobalt oxides with Raman scattering and fourier transform infrared spectroscopy. J. Phys. Chem. C 120, 4511-4516 (2016).

19. Zhang, A., Han, J., Su, B., Li, P. \& Meng, J. Microstructure, mechanical properties and tribological performance of $\mathrm{CoCrFeNi}$ high entropy alloy matrix selflubricating composite. Mater. Des. 114, 253-263 (2017).

20. Liu, Y. et al. Oxidation behavior of high-entropy alloys $\mathrm{Al}_{x} \mathrm{CoCrFeNi}(x=0.15,0.4)$ in supercritical water and comparison with HR3C steel. Trans. Nonferrous Met. Soc. China 25, 1341-1351 (2015).

21. Ayyagari, A. et al. Reciprocating sliding wear behavior of high entropy alloys in dry and marine environments. Mater. Chem. Phys. 210, 162-169 (2018).

22. Stachowiak, W. G. and Batchelor, A. W. Engineering Tribology 4th edn (Elsevier, Amsterdam, 2014).

23. Gao, X. et al. Microstructural origins of high strength and high ductility in an AlCoCrFeNi ${ }_{2.1}$ eutectic high-entropy alloy. Acta Mater. 141, 59-66 (2017).

24. Archard, J. Contact and rubbing of flat surfaces. J. Appl. Phys. 24, 981-988 (1953).

25. Leyland, A. \& Matthews, A. On the significance of the H/E ratio in wear control: a nanocomposite coating approach to optimised tribological behavior. Wear 246, 1-11 (2000).

26. Pintaude, G. Introduction of the Ratio of the Hardness to the Reduced Elastic Modulus for Abrasion. Tribology-Fundamentals and Advancements, Gegner, J. (Ed.) InTech (2013). https://doi.org/10.5772/55470.

27. Guo, J., Wang, H., Meng, F., Liu, X. \& Huang, F. Tuning the $H / E^{*}$ ratio and $E^{*}$ of AIN coatings by copper addition. Surf. Coat. Technol. 228, 68-75 (2013).

28. Zhang, L. et al. Study on the anodic film formation process of AZ91D magnesium alloy". Electrochim. Acta 52, 5325-5333 (2007).

29. Fattah-alhosseini, A. \& Vafaeian, S. Influence of grain refinement on the electrochemical behavior of AISI 430 ferritic stainless steel in an alkaline solution. Appl. Surf. Sci. 360, 921-928 (2016).

30. Lee, C. P., Chen, Y. Y., Hsu, C. Y., Yeh, J. W. \& Shih, H. C. Enhancing pitting corrosion resistance of $\mathrm{Al}_{\mathrm{x}} \mathrm{CrFe}_{1.5} \mathrm{MnNi}_{0.5}$ high-entropy alloys by anodic treatment in sulfuric acid. Thin Solid Films 517, 1301-1305 (2008).

31. Chen, Y., Duval, T., Hung, U., Yeh, J. \& Shih, H. Microstructure and electrochemical properties of high entropy alloys-a comparison with type-304 stainless steel. Corros. Sci. 47, 2257-2279 (2005).

32. Li, W. \& Li, D. Variations of work function and corrosion behaviors of deformed copper surfaces. Appl. Surf. Sci. 240, 388-395 (2005).

33. Li, W., Su, H. \& Yue, J. Effects of crystallization on corrosion resistance and electron work function of $\mathrm{Zr}_{65} \mathrm{Al}_{7 .}{ }_{5} \mathrm{Cu}_{17 .} \mathrm{Ni}_{10}$ amorphous alloys. Philos. Mag. Lett. 93, 130-137 (2013).

34. Ayyagari, A., Hasannaeimi, V., Arora, H. \& Mukherjee, S. Electrochemical and friction characteristics of metallic glass composites at the microstructural lengthscales. Sci. Rep. 8, 906 (2018).

35. Rohwerder, M. \& Turcu, F. High-resolution Kelvin probe microscopy in corrosion science: scanning Kelvin probe force microscopy (SKPFM) versus classical scanning Kelvin probe (SKP). Electrochim. Acta 53, 290-299 (2007).

36. Yee, S., Oriani, R. \& Stratmann, M. Application of a kelvin microprobe to the corrosion of metals in humid atmospheres. J. Electrochem. Soc. 138, 55-61 (1991).

37. Buckley, D. H. Surface effects in adhesion, friction, wear, and lubrication. (Elsevier, Cleveland, 1981).

38. Michaelson, H. B. Relation between an atomic electronegativity scale and the work function. IBM J. Res. Dev. 22, 72-80 (1978).

Open Access This article is licensed under a Creative Commons Attribution 4.0 International License, which permits use, sharing, adaptation, distribution and reproduction in any medium or format, as long as you give appropriate credit to the original author(s) and the source, provide a link to the Creative Commons license, and indicate if changes were made. The images or other third party material in this article are included in the article's Creative Commons license, unless indicated otherwise in a credit line to the material. If material is not included in the article's Creative Commons license and your intended use is not permitted by statutory regulation or exceeds the permitted use, you will need to obtain permission directly from the copyright holder. To view a copy of this license, visit http://creativecommons. org/licenses/by/4.0/.

(c) The Author(s) 2019 